The argument for extension is that this will result in more availability of the services provided by pubs in this country, but do we no longer believe that availability leads to abuse? Do people not realise that we have severe problems in this country with alcoholism and alcohol-related crimes? We know that there has been an increase in alcohol abuse over the recent past and that this is seen more frequently now, both among women and in younger age groups, but, despite this, opening times are paradoxically being extended.

It seems clear that some of the patients who attended alcoholism addiction units could only stay out of a pub if they were either too intoxicated to walk or if the door was shut. Alcohol is easily obtainable from off-licences, but keeping pubs open longer will increase its availability and its related problems. Furthermore, I would like to point out that the message some advertisements on television are trying to put across about alcoholic drinks is false or incomplete. Alcoholic drinks are made out to be able to relieve instantly the boredom and tediousness of life - life is filmed in black and white and depicts miserable looking people either pushing heavy boulders up hills or looking as though they are about to fall to pieces in a cobwebbed library - and replace it with happy, healthy looking people sitting comfortably in a bright, warm atmosphere. Is this the truth? What about the misery and suffering of alcohol-related illness, accidents and crimes? Obviously a non-seller.

The Ipswich Hospital

A. MaRKantonaKis

Ipswich, Suffolk

\section{Part-time training in psychiatry}

\section{DEAR SIRS}

I should like to respond to the letter from Dr Nancy

Darroch-Voloshanovich (Bulletin, July 1988).

I am reluctant to offer reassurance to $\mathrm{Dr}$ Darroch-Voloshanovich and her colleagues about the difficulties experienced by doctors who wish to train in psychiatry on a part-time basis, as I am aware that these are still substantial.

However, I do think that there is cause for hope.

A Joint Working Party between the Profession and the Department of Health was set up in January 1984, and I have been a member of it, representing the Joint Consultants' Committee and the Central Manpower Committee throughout. Having been a part-time trainee myself as a senior registrar, I have taken advantage of this to represent the needs of part-time trainees in psychiatry, as well as the views of the College on this matter.

As a result of the recent publication of Dr Isobel Allen's book on Doctors and their Careers, increased publicity is to be given to the ways in which part-time training can be obtained, as it has become increasingly clear that there is ignorance about this, as well as unhelpful attitudes, in members of our profession who occupy positions where they are looked to for career advice.

There is an articulate body of opinion in the medical profession that part-time training should be facilitated, particularly as the proportion of female medical students has now exceeded $50 \%$ in some intakes.

More specifically, there are individuals who have detailed knowledge about how the difficulties in obtaining part-time training can be overcome, and I recommend that anyone who is interested in availing themselves of such an opportunity should approach one of us.

Uffculme Clinic

F. CALdicotT

Queensbridge Road

Moseley, Birmingham B13 8QD

\section{AIDS and the psychiatrist}

\section{DeAr Sirs}

I am sure that Dr Katona is right when he suggests that psycho-geriatricians will be called upon to provide services for the more advanced cases of dementia due to the Human Immunodeficiency Virus (HIV) and that there is a need to be vigilant lest these services be provided at the expense of other patient groups (Bulletin, May 1988, 12, 187-188). In fact, I suspect that pressure will be exerted on all those with access to medium and long-stay beds to accommodate these unfortunate individuals, as already occurs with cases of presenile dementia and severe, incapacitating brain damage.

HIV is a new phenomenon in the UK and the various psychosyndromes associated with infection require varying degrees of special provision. This novelty demands new money: Her Majesty's Government has released funding for research into HIV, for the training and establishment of highly specialised personnel to advise on HIV-related problems and, of course, to combat drug abuse. The case must be made for additional monies to be made available from outside the Health Service to pay for the psychiatric provision that the HIV epidemic demands.

HIV encephalopathy is but one means by which young adults may be struck down and rendered brain-impaired to a degree that precludes independent life. I believe there is a clinical and administrative case to be made for grouping this 'forgotten cohort' so that humane and need-oriented services can be planned and provided. To this end I would suggest that the College should establish a working party to examine the needs of the young brain-damaged. The overburdened mental handicap 